\title{
IMPLIKASI HUKUM BAGI PPAT YANG TIDAK MENDAFTARKAN AKTA PPAT LEBIH DARI 7 (TUJUH) HARI KERJA KE KANTOR PERTANAHAN
}

\author{
Misranto \\ Magister Kenotariatan Universitas Islam Malang \\ Email: misranto.fh@gmail.com
}

Yuridika Galih Pratama Putra

Lembaga Pemberdayaan dan Perlindungan Masyarakat Jawa Timur

Email: yuridikagalih@yahoo.com

\begin{abstract}
Abstrak
Penelitian ini membahas mengenaiadanya pendaftaran akta PPAT ke kantor Pertanahan (BPN) yang melebihi dari 7 (tujuh) hari kerja setelah penandatanganan di kantor PPAT yang di daftarkan ke Kantor Pertanahan (BPN) Kabupaten Ponorogo oleh PPAT tersebut. Sedangkan jelas pada Pasal 40 ayat (1)PP 24/1997 tentang PendaftaranTanah menegaskan bahwa: "selambat-lambatnya 7 (tujuh) hari kerja sejak tanggalditandatanganinya akta yang bersangkutan, PPAT wajibmenyampaikan akta yang dibuatnya berikut dokumen-dokumenyang bersangkutan kepada Kantor Pertanahan (BPN) Kabupaten/Kota setempat sessuai wilayah kerja PPAT yang bersangkutan untuk didaftar'. Berdasarkan hasil penelitian yang dilakukan, bahwa terdapat beberapafaktor penghambat dalam penyampaian pendaftaran hak atas tanah oleh PPAT ke Kantor Pertanahan Kabupaten Ponorogo yaitu: 1. Kurangnya penyampaian berkas-berkas yang disampaikan klien kepada PPAT. Seperti: Sertipikat asli; Foto kopi KTP dan KK pihak penjual, apabila tanah tersebut merupakan harta bersama dengan istrinya maka dilampirkan pula foto kopi KTP istri dan foto kopi surat nikah; Foto kopi KTP dan KK pihak pembeli; Foto kopi Surat Pemberitahuan Pajak Terutang Pajak Bumi dan Bangunan (SPPT PBB) 5 (lima) tahun terakhir dan tahun berjalan/tahun terakhir, belum e-KTP; 2. Adanya suatu situasi yang mengharuskan PPAT terlambat mendaftarkan akta jual belinya dikarenakan ada hal yang harus dilakukan guna untuk menyelamatkan suatu transaksi jual beli. Pembuatan akta jual beli seperti ini terlihat dalam konstruksi transaksi jual beli dimana pajak-pajak terutang yang telah dibayar belum tervalidasi baik pajak pembeli (BPHTB) maupun pajak penjual (SSP PPh Final) pada saat penandatanganan akta dilakukan. 3. Terdapat rasa saling percaya yang sangat tinggi di antara sesama PPAT dan antara para pihak dengan PPATdan tidak akan terdapat masalah di kemudian hari yang dapat menyulitkan mereka. 4.Faktor waktu dan kesibukan dari PPAT, sehingga
\end{abstract}


menyebabkan PPAT tidak bisa mendaftarkan kewajibannya untuk mendaftarkan aktanya sebelum 7 hari kerja setelah penandatanganan akta PPAT tersebut.Implikasi hukum terkait dengan tindakan PPAT yang tidak melaksanakan kewajiban menyampaikan berkas pendaftaran tanah sebelum 7 (tujuh) hari kerja setelah penandatanganan ke Kantor Pertanahan Kabupaten Ponorogo adalah dengan cara mengukur sejauh mana ketentuan itu ditaati atau tidak ditaati oleh subyek hukumnya, dalam hal ini adalah PPAT. Terkait dengan hal tersebut, belum adanya hukum yang mengatur dengan tegas tentang sanksi bagi PPAT tersebut dari konsep struktur hukum. Tindakan hukum terhadap pendaftaran tanah yang didaftarkan oleh PPAT ke kantor Pertanahan (BPN) Kabupaten Ponorogo yang melebihi jangka waktu 7 (tujuh) hari, yaitu hanya dikenai teguran lisan dan teguran tertulis yang disampaikan kepada PPAT bersangkutan dan kepada organisasi IPPAT, sedangkan untuk pendaftaran hak atas tanah tetap diproses oleh Kantor Pertanahan.

Kata Kunci: Pendaftaran Tanah, PPAT, Sanksi

\section{Abstract}

This research discusses the existence of Land Deed Maker Officer (PPAT) deed registration to the Land Office (BPN) which is more than 7 (seven) working days after the signing at the Land Deed Maker Officer (PPAT) office which is registered with the Ponorogo Regency Land Office (BPN) by the Land Deed Maker Officer (PPAT). Meanwhile, it is clear in Article 40 paragraph (1) PP 24/1997 concerning Land Registration that: "no later than 7 (seven) working days from the signing date of the deed concerned, Land Deed Maker Officer (PPAT) is obliged to submit the deed made along with the relevant documents to the Office. Local Regency / City Land(BPN) in accordance with the Land Deed Maker Officer (PPAT) working area concerned to be registered '. Based on the results of the research conducted, there are several inhibiting factors in submitting registration of land rights by Land Deed Maker Officer (PPAT)to the Ponorogo Regency Land Office, namely: 1. Lack of submission of files submitted by clients to Land Deed Maker Officer (PPAT). Such as: original certificate; A photocopy of the seller's identy card population (KTP) and family card $(K K)$, if the land is joint property with his wife, then a copy of the wife's identy card population (KTP) and a copy of the marriage certificate shall also be attached; Photocopy of the buyer's identy card population (KTP) and family card (KK); Photocopy of Land and Building Tax Payable Tax Return (SPPT PBB) for the last 5 (five) years and current I last year, not yet electronic identy card population (e-KTP); 2. There is a situation that requires Land Deed Maker Officer (PPAT) to be late in 
registering its sale and purchase deed because there are things that must be done in order to save a sale and purchase transaction. The making of a sale and purchase deed like this can be seen in the construction of a sale and purchase transaction where the payable taxes that have been paid have not been validated, either the buyer tax (BPHTB) or the seller tax (SSP PPh Final) at the time the deed is signed. 3. There is a very high sense of mutual trust between Land Deed Maker Officer (PPAT) and between the parties and Land Deed Maker Officer (PPAT) and there will be no problems in the future that could make it difficult for them. 4. The time factor and the busyness of the Land Deed Maker Officer (PPAT), thus causing Land Deed Maker Officer (PPAT) to be unable to register its obligation to register its deed before 7 working days after signing the Land Deed Maker Officer (PPAT) deed. The legal implication related to Land Deed Maker Officer (PPAT) friends action that does not carry out the obligation to submit land registration documents before 7 (seven) working days after signing to the Ponorogo Regency Land Office is by measuring the extent to which the provisions are adhered to or not obeyed by its legal subjects, in this case Land Deed Maker Officer (PPAT). In this regard, there is no law that clearly regulates the sanctions for Land Deed Maker Officer (PPAT) from the concept of a legal structure. Legal action against land registration registered by Land Deed Maker Officer (PPAT) at the Ponorogo Regency Land Office (BPN) which exceeds a period of 7 (seven) days is only subject to verbal and written warnings submitted to the relevant Land Deed Maker Officer (PPAT) and to the Land Deed Maker Officer Unity (IPPAT) organization, while registration of rights to land is still being processed by the Land Office.

Keywords: Land Registration, Land Deed Maker Officer (PPAT), Sanctions

\section{PENDAHULUAN}

Sejalan dengan perkembangan masyarakat serta pesatnya pembangunan di segala bidang dan mengingat kondisi Negara Republik Indonesia yang bercorak agraris, maka jelas tanah tetap mempunyai peranan penting bagi dan bangsa Indonesia.Pentingnya tanah bagi Negara dan bangsa Indonesia, menyebabkan pembentuk Undang-Undang Dasar Negara 1945 yang selanjutnya dalam tulisan ini disebut UUD 1945, merasa wajib merumuskan pasal mengenai peraturan bahwa bumi dan air serta kekayaan alam yang terkandung didalamnya untuk kepentingan kehidupan bangsa Indonesia. Untuk itu pasal 33 ayat (3) UUD 1945 menentukan bahwa bumi dan air dan kekayaan alam yang terkandung didalamnya dikuasai oleh Negara dan dipergunakan sebesar-besarnya untuk kemakmuran 
rakyat.Dalam Pasal 33 ayat (3) UUD 1945tersebut, dapatlah diketahui bahwa hak-hak Negara dan pemerintah terhadap tanah bersifat menguasai, bukan memiliki.

Dengan berlakunya Undang-Undang Nomor 5 Tahun 1960 tentang Peraturan Dasar Pokok-Pokok Agraria yang diundangkan pada tanggal 24 September 1960 dalam Lembaran Negara Republik Indonesia tahun 1960 nomor 104 dan penjelasannya dimuat dalam Tambahan Lembaran Negara Republik Indonesia Nomor 2043, yang selanjutnya dalam tulisan ini disebut UUPA, diberikan penjelasan resmi mengenai sifat dan lingkup hak menguasai dari Negara bahwa penguasaan tanah oleh Negara menurut UUPA bersifat "hukum publik". Adapun bentuk penguasaan Negara atas tanah, dapat diamati dalam Pasal 2 ayat (2) UUPA yang berbunyi sebagai berikut:

1. Mengatur dan menyelenggarakan peruntukan, penggunaan, penyediaan dan pemeliharaan bumi dan air dan ruang angkasa

2. Menentukan dan mengatur hubungan-hubungan hukum antar orang-orang dengan bumi, air dan ruang angkasa

3. Menentukan dan mengatur hubungan-hubungan hukum antara orangorang dan perbuatan-perbuatan hukum yang mengenai bumi, air dan ruang angkasa.

Adapun tujuan diundangkan UUPA sebagaimana yang dimuat dalam penjelasan umumnya, yaitu:

1. Meletakkan dasar-dasar bagi penyusunan hukum agraria nasional, yang akan merupakan alat untuk membawakan kemakmuran,kebahagiaan dan keadilan bagi Negara dan rakyat, terutama rakyat tani, dalam rangka masyarakat adil dan makmur;

2. Meletakkan dasar-dasar untuk mengadakan kesatuan dan kesedeharnaan hukum pertanahan

3. Meletakkan dasar-dasar untuk memberikan kepastian hukum mengenai hak-hak atas tanah bagi rakyat seluruhnya

Pemberian jaminan kepastian hukum mengenai hak-hak atas tanah bagi seluruh rakyat Indonesia, yang menjadi salahsatu tujuan diundangkannya UUPA dapat terwujud melalui dua upaya yang secara garis besarnya, yaitu:

1. Tersedianya perangkat hukum yang tertulis, lengkap dan jelas yang dilaksanakan secara konsisten sesuai dengan jiwa dan ketentuanketentuannya.

2. Penyelenggaraanpendaftaran tanah yang memungkinkan bagi pemegang hak atas tanah untuk dengan mudah membuktikan hak atas tanah yang dikuasainya, dan bagi pihak yang berkepentingan, seperti calon pembeli dan calon kreditur, untuk memperoleh keterangan yang 
diperlukan mengenai tanah yang menjadi objek perbuatan hukum yang akan dilakukan, serta bagi pemerintah untuk melaksanakan kebijaksanaan pemerintahan.

Pendaftaran tanah yang bertujuan memberikan jaminan Kepastian Hukum dikenal dengan sebutan Rechts Cadaster/Legal Cadaster. Ketentuan tentang kewajiban bagi pemerintah untuk menyelenggarakan pendaftaran tanah diseluruh wilayah Republik Indonesia diatur dalam pasal 19 ayat (1) UUPA, yaitu:"untuk menjamin Kepastian Hukum oleh pemerintah diadakan pendaftaran tanah diseluruh wilayah Republik Indonesia menurut ketentuanketentuan yang diatur dengan Peraturan Pemerintah.”

Persoalan penyelenggaraan pandaftaran tanah mengenai tanah-tanah di Indonesia baru mendapat penyelesaian secara prinsipil dengan diundangkannya UUPA sebagai dasar pelaksanaan pendaftaran tanah di Indonesia. Ketentuan lebih lanjut mengenai pendaftaran tanah menurut pasal 19 ayat (1) UUPA diatur dengan menggunakan Peraturan Pemerintah, yaitu Peraturan Pemerintah nomor 24 Tahun 1997 tentang Pendaftaran Tanah, selanjutnya disebut PP 24/1997. Dalam ketentuan umum pasal 1 PP 24/1997 ditentukan bahwa:"Pendaftaran tanah adalah rangkaian kegiatan yang dilakukan oleh pemerintah secara terus-menerus, berkesinambungan dan teratur, meliputi pengumpulan, pengolahan, pembukuan dan penyajian serta pemeliharaan data fisik dan data yuridis, dalam bentuk peta dan daftar mengenai bidang-bidang tanah dan satuan-satuan rumah susun, termasuk pemberian sertifikat sebagai surat tanda bukti haknya bagi bidang-bidang tanah yang sudah ada haknya dan Hak Milik Satuan Rumah Susun serta hak-hak tertentu yang membebaninya".

Sejak berlakunya UUPA, khususnya setelah diberlakukannya PP 24/1997, setiap perjanjian yang bermaksud memindahkan hak atas tanah, membebankan hak atas tanah sebelum didaftar harus dibuktikan dengan akta yang dibuat dihadapan Pejabat Pembuat Akta Tanah (PPAT) yang ditunjuk oleh menteri.

Embrio institusi Pejabat Pembuat Akta Tanah (PPAT)yang selanjutnya dalam tulisan ini disebut PPAT telah ada sejak tahun 1961 berdasarkan Peraturan Pemerintah Republik Indonesia Nomor 10 Tahun 1961 tentang Pendaftaran Tanah, selanjutnya disebut PP 10/1961,bahwa yang dimaksud pejabat adalah PPAT disebutkan dalam Peraturan Menteri Negara Agraria Nomor 11 tahun 1961 tentang bentuk akta. Pada awal kelahirannya PPAT tidak dikategorikan sebagai pejabat umum kemudian berdasarkan Pasal 1 ayat (4) Undang-undang Nomor 4 Tahun 1996 tentang Hak Tanggungan atas tanah beserta benda-benda yang berkaitan dengan tanah, yang selanjutnya dalam tulisan ini disebut UUHT, bahwa:"Pejabat 
Pembuat Akta Tanah (PPAT) adalah Pejabat umum yang diberi wewenang untuk membuat akta pemindahan hak atas tanah, akta pembebanan hak atas tanah, dan akta pemberian kuasa membebankan Hak Tanggungan menurut peraturan perundang-undangan yang berlaku".

Kemudian keberadaan PPAT ditegaskan dalam pasal 1 angka 24 PP 24/1997 tentang Pendaftaran Tanah bahwa: "Pejabat pembuat akta tanah, sebagaimana disebut PPAT adalah Pejabat Umum yang diberi kewenangan untuk membuat akta-akta tanah tersebut". Secara khusus keberadaan PPAT diatur dalam Peraturan Pemerintah Nomor 37 Tahun 1998 tentang Peraturan Jabatan Pejabat Pembuat Akta Tanah, yang selanjutnya disebut PP 37/1998. Dalam pasal 1 ayat (1) PP 37/1998 ditentukan bahwa:"PPAT adalah pejabat Umum yang diberi kewenangan untuk membuat akta-akta otentik mengenai perbuatan hukum tertentu mengenai hak atas tanah atau hak milik atas satuan rumah susun."

Berdasarkan hal tersebut, PPAT diberi kewenangan membuat akta PPAT otentik. Menurut Kamus Besar Bahasa Indonesia, "membuat adalah menciptakan, melakukan, mengerjakan”. Dalam artian, PPAT mempunyai kewenangan menciptakan, membuat dan mengerjakan sendiri akta PPAT yang menjadi kewenangannya sebagaimana ditentukan dalam Pasal 95 PP 37/1998.Bertalian dengan PP 24/1997 tentang PendaftaranTanah menegaskan bahwa Pasal 40 ayat (1): "selambat-lambatnya 7 (tujuh) hari kerja sejak tanggalditandatanganinya akta yang bersangkutan, PPAT wajibmenyampaikan akta yang dibuatnya berikut dokumen-dokumenyang bersangkutan kepada Kantor PertanahanKabupaten/Kota setempat sessuai wilayah kerja PPAT yang bersangkutan untuk didaftar'. Sistem pendaftaran tanah dalam hal ini adalah sistem pendafataran tanah sporadik.

Dari rumusan bunyi pasal diatas, dikatakan bahwa akta PPAT digunakan sebagai bukti yang akan dijadikan dasar bagi pendaftaran tanah Kantor Pertanahan Kabupaten/Kota setempat sessuai wilayah kerja PPAT tersebut yang hanya berlaku selama 7 (tujuh) hari kerja,hal tersebutdiatas jelas bahwa adanya kewajiban yang harusdilaksanakan oleh PPAT dan tidak boleh dilalaikan gunamembantu kelancaran proses pendaftaran tanah di Kantor Pertanahan

Kabupaten/Kota setempat sesuai wilayah kerja PPAT yang bersangkutan. Dalam praktiknya, di kantor PPAT Ibu Mardiana Maruwi, SH salah satu PPAT Kabupaten Ponorogo, terdapat beberapa berkas yang pendaftarannya melebihi dari 7 (tujuh) hari kerja setelah penandatanganan di kantor PPAT tersebut, seperti salah satu contoh kasus untuk berkas Jual-Beli pihak penjual yaitu bapak Setia Budi dan pihak pembeli bapak Agus Basuki, yang telah melakukan tanda tangan Akta Jual Beli (AJB) di kantor PPAT Ibu Mardiana Maruwi, SH., dikarenakan pajak-pajaknya belum terselesaikan 
atau belum tervalidasi, dengan lamanya proses berkas di Dinas Pendapatan Daerah Kabupaten Ponorogo dan lamanya proses berkas di Kantor Pelayanan Pajak Pratama Ponorogo, menyebabkan lamanya masuk berkas ke Kantor Pertanahan (BPN) Kabupaten Ponorogo atau pendaftarannya telah lebih dari 7 (tujuh) hari kerja, hal tersebut telah jelas melanggar Pasal 40 ayat (1) dari PP 24/1997.

\section{METODE PENELITIAN}

Jenis penelitian yang digunakan oleh peneliti yaitu menggunakan Yuridis Empiris untuk mengkaji tentang pokok permasalahan dalam penelitian ini penulis menggunakan pendekatan Yuridis Sosiologis, untuk itu yang menjadi fokus dan sentral dalam penelitian ini adalah untuk menelaah dan mengetahui faktor-faktor penyebab PPAT terlambat mendaftarkan aktanya ke Kantor Pertanahan lebih dari 7 (tujuh) hari kerja setelah penandatanganan di PPATdan menganalisis implikasi hukum bagi para pihak yang dirugikan atas keterlambatan mendaftarkan aktanya ke Kantor Pertanahan lebih dari 7 (tujuh) hari kerja setelah penandatanganan di PPAT, dan untuk membuat bentuk perlindungan hukum baru bagi para pihak atas kepastian akta PPAT yang tidak didaftarkan ke Kantor Pertanahan lebih dari 7 (tujuh) hari kerja setelah penandatanganannya. Sumber data yang diginakan dalam penelitian ini adalah data primer dan data sekunder. Teknik pengumpulan data yang digunakan dalam peneletian ini adalah wawancara, observasi, dan dokumentasi.

\section{PEMBAHASAN}

\section{A. Penyebab PPAT Terlambat Mendaftarkan Aktanya Ke Kantor Pertanahan Lebih Dari 7 (Tujuh) Hari Kerja Setelah Penandatanganan Di PPAT Dipengaruhi Oleh Beberapa Faktor.}

Faktor-faktor penyebab PPAT terlambat mendaftarkan aktanya ke kantor pertanahan lebih dari 7 (tujuh) hari kerja setelah penandatanganan di PPAT dilapangan yang menyebabkan terjadinya pembuatan akta-akta oleh PPAT terlambat didaftarkan pada Kantor Pertanahan setempat. ParaPPAT tersebut sebenarnya juga sadar dan mengetahui bahwa terdapat konsekuensi terhadap apa yang mereka lakukandalam hal pembuatan akta jual beli akta PPAT, akan tetapi mereka tetap melakukan hal-haltersebut oleh karena ada keyakinan bahwa seandainya mereka tidakmenerima atau tidak mau untuk melakukan perbuatan seperti itumereka akan kehilangan klien, karena klien mereka akan berpindahdan mempergunakan jasa PPAT lain. 

adalah: ${ }^{1}$

Faktor-faktor yang menyebabkan hal-hal tersebut di atas antaralain

1. Adanya Kartu Tanda Penduduk (KTP) yang tidak bisa didaftarkan secara online oleh pihak PPAT karena belum terdaftar di Kementerian Dalam Negeri, yang menyebabkan pemilik Kartu Tanda Penduduk harus meminta validasi di Dinas Kependudukan dan Catatan Sipil (belum eKTP).

2. Adanya suatu situasi yang mengharuskan PPAT terlambatmendaftarkan akta jual belinya dikarenakan ada hal yang harus dilakukan guna untuk menyelamatkan suatu transaksi jual beli. Pembuatan akta jual beli seperti ini terlihatdalam konstruksi transaksi jual beli dimana pajak-pajak terutang yang telah dibayar belum tervalidasi baik pajak pembeli (BPHTB) maupun pajak penjual (SSP PPh Final) pada saatpenandatanganan akta dilakukan.

3. Faktor waktu dan kesibukan dari PPAT, sehingga menyebabkan PPAT tidak bisa mendaftarkan kewajibannya untuk mendaftarkan aktanya sebelum 7 hari kerja setelah penandatanganan akta PPAT tersebut.

Dari macam-macam faktor dan alasan tersebut, terdapat kemungkinan adanya kombinasi daribeberapa faktor dan alasan dalam hal keterlambatan pendaftaran akta ke Kantor Pertanahan (BPN). Jadi terdapatkemungkinan satu transaksi jual beli, pembuatan aktanya dilakukandengan satu atau lebih cara yang tidak sesuai dengan tata carapembuatan akta PPAT. Dan disuatu sisi PPAT berusaha untuk sesuai dengan peraturan yang berlaku.

\section{B. Implikasi Hukum Bagi Pejabat Pembuat Akta Tanah (PPAT) Atas Keterlambatan Mendaftarkan Aktanya Ke Kantor Pertanahan Lebih Dari 7 (Tujuh) Hari Kerja Setelah Penandatanganan Di PPAT Di Kabupaten Ponorogo.}

Peranan penegak hukum dalam arti fungsi dan maknanya merupakan bagian dari konsep struktur hukum dan seharusnya peran organisasi Ikatan Pejabat Pembuat Akta Tanah (IPPAT) sangat besar dan sangat dibutuhkan dalam hal ini membuat sebuah sistem hukum atau aturan hukum yangmempunyai struktur dan yang memilikisubstansi, meliputi aturan, norma dan perilaku nyata manusia yang berada didalam sistem itu yaitu PPAT. Termasuk pula dalam pengertian substansi ini adalah semua produk, seperti keputusan, aturan baru yang disusun dan dihasilkan oleh orang yang berada di dalam sistem itu pula, yang ketiga aspek budaya hukum dalam PPAT meliputi kepercayaan, nilai, pemikiran serta harapannya. Struktur dapat diibaratkan sebagai mesin. Substansi adalah apa yang dihasilkan atau dikerjakan oleh mesin itu. Budaya hukum (legal culture) adalah apa saja

${ }^{1}$ Wawancara dengan Ibu Mardiana Maruwi, SH., Notaris-PPAT Kabupaten Ponorogo,pada tanggal 10 April 2020. 
atau siapa saja yang memutuskan untuk menghidupkan dan mematikan mesin itu, serta bagaimana mesin itu harus digunakan agar adanya efektifitas hukum.

Masih adanya berkas pendaftaran tanah yangsudah masuk di Kantor Pertanahan Kabupaten Ponorogo untuk didaftar,beberapa proses pendaftaran tanah tersebut mengalami keterlambatan dalam pengirimannyake Kantor Pertanahan Kabupaten Ponorogo yang dilakukan oleh PPAT diKabupaten Ponorogo tersebut terlihat dari tanggal penandatanganan akta contohnya akta jual beli dengan tanggal masuk atau diterima berkas tersebut di Kantor Pertanahan Kabupaten Ponorogo.

C. Tindakan Hukum Yang Dilakukan Kantor Pertanahan Kabupaten Ponorogo Bagi PPAT Yang Mendaftarkan Aktanya Ke Kantor Pertanahan Kabupaten Ponorogo Lebih Dari 7 Hari Kerja Setelah Penandatangan.

Penyerahan berkas pendaftaran tanah ke Kantor Pertanahan Kabupaten Ponorogo sebagaimana yang dipraktekkan oleh sebagian besar PPAT di Kabupaten Ponorogo tersebut tidak sesuai dengan ketentuan perundang-undangan yangberlaku, namun tidak mengakibatkan batalnya proses pendaftaran tanah yang dimaksud dan tidak ada satu ketentuan hukum pun yang menyatakan bahwadengan keterlambatan penyerahan berkas pendaftaran tanah tersebut menjadikan akta yangbersangkutan batal.

Menyikapi kinerja PPAT yang demikian penulis menelaah menggunakan teori kewenangan yaitu tidak dapat dilepaskandari fungsi Kepala Kantor Pertanahan dalam hal ini Kepala Kantor Pertanahan Kabupaten Ponorogo sebagai instansiyang diberi kewenangan untuk melakukan pembinaan dan pengawasankepada PPAT di wilayahnya.Dengan adanya ketentuan dalam pasal-pasal mengenai pendaftaran tanah yangharus sesuai dengan peraturan perundang-undangan yangberlaku dan juga tentang sanksi administrasi yang diberikan kepada PPATyang melakukan kelalaiannya tersebut diatas, maka dalam penyelesaianmengenai keterlambatan penyerahan berkas pendaftaran tanah yang dilakukan oleh PPAT keKantor Pertanahan Kabupaten Ponorogo. Kantor Pertanahan Kabupaten Ponorogo sebagai instansi pemerintah yang berwenang dalam mengawasikinerja PPAT di Kabupaten Ponorogo harus memberikan pengarahan danteguran, baik itu teguran lisan maupun tertulis kepada PPAT yang tidakmelakukan tugasnya dengan baik agar PPAT di wilayah Kabupaten Ponorogo menjadi lebih disiplin dalam melakukan pekerjaannya sebagai PPAT.

\section{KESIMPULAN}


Ada tiga faktor penghambat dalam penyampaian pendaftaran hak atas tanah oleh PPAT ke Kantor Pertanahan Kabupaten Ponorogo yaitu:

1)Adanya Kartu Tanda Penduduk (KTP) yang tidak bisa didaftarkan secara online oleh pihak PPAT karena belum terdaftar di Kementerian Dalam Negeri, yang menyebabkan pemilik Kartu Tanda Penduduk harus meminta validasi di Dinas Kependudukan dan Catatan Sipil (belum e-KTP).

2) Adanya suatu situasi yang mengharuskan PPAT terlambatmendaftarkan akta jual belinya dikarenakan ada hal yang harus dilakukan guna untuk menyelamatkan suatu transaksi jual beli. Pembuatan akta jual beli seperti ini terlihatdalam konstruksi transaksi jual beli dimana pajak-pajak terutang yang telah dibayar belum tervalidasi baik pajak pembeli (BPHTB) maupun pajak penjual (SSP PPh Final) pada saatpenandatanganan akta dilakukan.

3) Faktor waktu dan kesibukan dari PPAT, sehingga menyebabkan PPAT tidak bisa mendaftarkan kewajibannya untuk mendaftarkan aktanya sebelum 7 hari kerja setelah penandatanganan akta PPAT tersebut.

Implikasi hukum terkait dengan tindakan PPAT yang tidak melaksanakan kewajiban menyampaikan berkas pendaftaran tanah sebelum 7 (tujuh) hari kerja setelah penandatanganan ke Kantor Pertanahan Kabupaten Ponorogo adalah belum adanya hukum yang mengatur dengan tegas tentang sanksi bagi PPAT yang tidak melaksanakan penyampaian berkas pendaftaran tanah sebelum 7 (tujuh) hari kerja setelah penandatanganan ke Kantor Pertanahan (BPN).

Tindakan hukum terhadap pendaftaran tanah yang didaftarkan oleh PPAT ke kantor Pertanahan Kabupaten Ponorogo yang melebihi jangka waktu 7 (tujuh)hari kerja yaitu hanya dikenai sanksi administratif saja yang berupateguran lisan dan teguran tertulis yang disampaikan kepada PPAT bersangkutan dan kepada organisasi IPPAT, sedangkan untuk pendaftaran hak atas tanah tetap diproses oleh Kantor Pertanahan. Sedangkan sanksi administratif yang berupa pemberhentian sementara dari jabatan danpemberhentian dari jabatan tidak dilakukan oleh Kantor Pertanahan Kabupaten Ponorogo.

Agar PPAT lebih berhati-hati dan lebih cepat bekerja dalam melakukan tugas jabatannya sebagai PPAT, diharapkan untuk melengkapi berkas-berkas terlebih dahulu seperti kelengkapan-kelengkapan formil dan pajak-pajaknya sebelum dilakukannya penandatanganan akta PPAT, dan dibutuhkannya pengawasan dari organisasi PPAT yaitu IPPAT mulai dari 
pengurus daerah, pengurus wilayah hingga pengurus pusat dan dari semua unsur, terhadap PPAT dan Kantor Pertanahan seluruh Indonesia.

AgarBPN berkoordinasi dengan IPPAT dalam hal menindak PPAT yang melakukan pendaftaran akta PPAT-nya lebih dari 7 hari kerja ke Kantor pertanahan, yang akan dikenai sanksi administratif yang berupateguran lisan dan teguran tertulis saja dan pendaftaran hak atas tanah tetap diproses oleh Kantor Pertanahan. Sedangkan sanksiadministratif yang berupa pemberhentian sementara dari jabatan danpemberhentian dari jabatan tidak dilakukan oleh Kantor Pertanahan Kabupaten Ponorogo.

Bagi para pihak Klien dari pada PPAT untuk mempersiapkan berkas-berkasnya terlebih dahulu dan pembayaran pajak-pajaknya terlebih dahulu sebelum ke kantor PPAT, agar pihak PPAT dapat memproses berkas-berkas tersebut dengan cepat dan mudah.

\section{DAFTAR PUSTAKA}

\section{Buku}

Achmad Ali, Menguak Teori Hukum ( Legal Theory) dan Teori Peradilan(Judicialprudence) Termasuk Interprestasi Undang Undang(Legisprudence), Jakarta :Prenada Media Group, 2009

Adrian Sutedi, Perihal Hak Atas Tanah Dan Pendaftarannya, Jakarta :Sinar Grafika, 2009.

Boedi Harsono, Hukum Agraria, Indonesia, Jakarta : Djambatan, 2008.

Daryanto,S.S, Kamaus Bahasa Indonesia Lengkap, Surabaya : Apollo, 1997 Jimly Asshiddiqie, Komentar Atas Udang-undang Dasar Negara Republik Indonesia Tahun 1945, Jakarta: Sinar Grafika, 2009

Lumban Tobing G.H.S, Ilmu Perundang-undangan, Jenis, Fungsi, danMateri Muatannya, Yogyakarta: Kanisius, 2007

Mhd Yamin Indrati dan Rahim Lubis, Hukum Pendaftaran Tanah, Medan:Mandar Maju, 2008

Muhammad Bakri, Hak Menguasai Tanah Oleh Negara ( paradigm baru untuk reformasi agrarian), Yogyakarta, Citra Media Hukum, 2007

Moh. Kusnardi dan Harmaily Ibrahim, Pengantar Hukum Tata NegaraIndonesia, Jakarta: Pusat Studi Hukum Tata Negara Fakultas HukumUniversitas Indonesia, 1996

Suko Wiyono, Otonomi Daerah Dalam Negera Hukum Indonesia, Jakarta:Faza Media, 2006

Supardi, Etika \& Tnggung Jawab Profesi Hukum di Indonesia, Jakarta:SinarGrafika, 2006

, Hukum Agraria, Jakarta; Sinar Grafika, 2008

Tim Penyusun Kamus-Pusat Prmbinaan dan Pengembsangan Bahasa,Kamus Besar Bahasa Indonesia, Jakarta, Balai Pustaka, 1989 
Urip Santoso, Pendaftaran dan Peralihan Hak atas Tanah, Jakarta:Kencana, 2010

Van Wijik/Willem Konijnenbelt HD, Hoodstukken van Administratief Recht,Culembong,Utigeverij LEMMA BV, 1998

Yan Pramadya Puspa, Kamus Hukum Edisi Lengkap Bahasa Belanda,Indonesi, Ingris, Semarang: Aneka Ilmu, 1977

\section{Peraturan Perundang-Undangan}

Undang-Undang Dasar 1945

Undang-Undang Republik Indonesia Nomor 5 Tahun 1960 tentang Peraturan Dasar Pokok-pokok Agraria.

Undang-Undang Republik Indonesia Nomor 4 Tahun 1960 tentang Hak Tanggungan Atas Tanah Besrta Benda-benda Yang Berkaitan Dengan Tanah

\section{Jurnal dan Makalah}

Ibrahim, R, Status Hukum Internasionaldan Perjanjian InternasionalDalam Hukum Nasional: Permasalahan Teoristik dan Praktik, MakalahDisajikan dalam Lokakarya Evaluasi IUU No.24 Tahun 2000 TentangPerjanjian Internasional, Diskusi Terbatas: Posisi Perjanjian Internasional Di Dalam Sistem Hukum Tata Negara, Kerjasama Departmen Luar Negeri Republik Indonesia Universitas Airlangga, Surabaya, 18 Oktober 2008

Philipus M. Hadjon, Eksistensi dan Fungsi Penjabat Pembuat Akta Tanah(PPAT) serta Figur Hukum Akta PPAT, Makalah Ceramah FakultasUNAIR Tanggal 22 Pebruari 1996

Wawan Setiawan, Kedudukan dan Keberadaan Serta Fungsi dan PerananPejabat Pembuat Akta aTanah Menurut Sistem Hukum Indonesia, Makalah Refreshing Up Grading Course INI, Jakarta, 1999

\section{Internet}

Habib Adjie, "Beda Karakter Yuridis Antara Notaris dan PPAT”,diaksesdi:http://www.notarisppatindonesia@googlegroups.c om, pada 3 Januari 2020

Kesupelan, Persahabatan, Persaudaraan, Saling Menghormati, Keramahtamahan, Keserasian, http://id.w3dictionary.org/PPAT, diakses pada tanggal 20 Mei 2020, pukul 21.35 WIB. 